\title{
Etiology of major limb amputations at a tertiary care centre in Malawi
}

\author{
Joanna Grudziak ${ }^{1}$, Cornelius Mukuzunga ${ }^{2}$, Caroline Melhado ${ }^{3}$, Sven Young ${ }^{2,4,5}$, Leonard Banza ${ }^{3,5,6}$, \\ Bruce Cairns ${ }^{1}$, Anthony Charles ${ }^{1,2,3}$
}

\author{
1. Department of Surgery, University of North Carolina at Chapel Hill, USA \\ 2. Department of Surgery, Kamuzu Central Hospital, Lilongwe, Malawi \\ 3. UNC Project, Malawi \\ 4. Department of Orthopaedic Surgery, Haukeland University Hospital, Bergen, Norway \\ 5. University of Malawi College of Medicine, Lilongwe, Malawi \\ 6. Institute of Clinical studies (K1) and Centre for International Health, University of Bergen, Norway
}

\begin{abstract}
Introduction
Amputations in low- and middle-income countries (LMICs) represent an important cause of disability and economic hardship. LMIC patients are young and suffer from preventable causes, such as trauma and trauma-related infections. We herein studied the etiology in amputations in a Malawian tertiary care hospital over a 9-year period.

Methods

Operative and anaesthesia logs at Kamuzu Central Hospital (KCH) in Lilongwe, Malawi, were reviewed for 2008-2016. Baseline demographic and clinical variables and type of amputation performed were collected. Only major limb amputations, defined as above or below the knee, above or below the elbow, and above the wrist, were included in this study.

Results

A total of 610 patients underwent 630 major amputations during the study period. Of these, $170(27 \%)$ patients were female, and the median age of the cohort was 39 (interquartile range [IQR] 25-55). Of these patients, $345(54.8 \%)$ had infection or gangrene recorded among the indications for amputation, $203(32.2 \%)$ had trauma, $94(14.9 \%)$ had cancer and $67(10.6 \%)$ had documented diabetes. Women underwent diabetes-related amputations more often than men (37 out of 67 , or $56.1 \%)$, and were significantly younger when their amputations were due to diabetes (median age 48 vs 53 years old, $\mathrm{P}=0.004$ ) or trauma (median age 21 vs 30 years old, $\mathrm{P}=0.02$ ). The commonest operative procedures were below the knee amputations, at 271 (43\%), and above the knee amputations, at 213 (33.8\%). Conclusion

Amputations in Malawi affect primarily the young, in the most economically productive time of their lives, in contrast to amputees in high-income countries. Preventable causes, such as infection and trauma, lead to the majority of amputations. These etiologies represent an important primary prevention target for public health efforts in LMICs.
\end{abstract}

\section{Key Words}

Major amputations, Malawi, traumatic amputations, low- and middle-income countries (LMIC), sub-Saharan Africa

\section{Introduction}

Amputees in low- and middle-income countries (LMICs) represent a formidable rehabilitative and integrative challenge, with a significant burden of disability shouldered by the individual. The physical, psychological, social and economic consequences of amputations are devastating to individuals, families, and society as a whole. In sub-Saharan Africa (SSA), women with disability have a $54 \%$ higher number of years lived with disability than do those in Europe, and $21 \%$ higher than women in Asia (16\% higher for men relative to both regions $)^{1}$. Major limb amputation is one of the most ancient of all surgical procedures with a history of more than 2500 years $^{2}$, and has been used for punitive, ritual and therapeutic reasons, including trauma, peripheral vascular disease, neoplasia, infection and congenital anomalies ${ }^{3}$. Limb amputation is considered an operative intervention of last resort when limb salvage is impossible, when the limb is viable but nonfunctional, or when it endangers the patient's life $^{4}$. In LMICs the inability to access adequate rehabilitative and prosthetic services frequently precludes the amputee from returning to a functional status ${ }^{5}$.

The etiology and incidence of amputations in LMICs differs from that of high-income countries (HICs) ${ }^{6,7}$. In HICs, diabetic vasculopathy or neuropathy is the most common etiology, followed by peripheral vascular disease, trauma and neoplasia; furthermore, patients are usually in the sixth to eighth decades of life $^{7-9}$. In North America, 3.6 million people are projected to suffer from limb loss by the year $2050^{8}$. Although there is a dearth of data on the incidence, etiology and outcomes of major amputations in SSA, available data suggest that the amputee population is much younger, with the majority being under 40 years of age $\mathrm{e}^{10-12}$. This contrasting age distribution may reflect the differing etiologies of amputation in SSA ${ }^{10,11,13}$.

Malawi, a land-locked southeastern African nation, had a GDP of US $\$ 340 /$ person in $2014^{14}$, and perennially ranks among the world's five poorest nations. The economy is dependent on subsistence farming, the majority of workers engage in physical labour, and adults are almost universally employed: $98 \%$ of $50-64$ year olds and $90 \%$ of adults aged $65+$ reported labour force participation in $2009^{1}$. Over $90 \%$ of women working outside the home participated in agricultural labour in 2013 ${ }^{15}$. This predominance of physically demanding occupations makes physical disability a livelihood- and life-threatening condition. For example, a study based on survey data in Malawi estimated that a 
55 -year-old male reporting severe physical limitations from disability contributed only half the farm labour of his healthy counterpart ${ }^{1}$. The purpose of this study was to describe the indications and patient characteristics of amputees in Malawi.

\section{Methods}

This is a retrospective analysis of major limb amputations performed at Kamuzu Central Hospital $(\mathrm{KCH})$ from January 2008 to December 2016. KCH is a public, 900-bed, tertiary care centre in the capital, Lilongwe, with a catchment population of over 6 million. It receives referrals from local district hospitals in the region of Central Malawi.

Operative and anaesthesia theatre logs were reviewed for the general surgery and orthopaedic services. The following data variables were collected: age, sex, date of surgery, indication for amputation and type of amputation performed. Adult (age 16 years and older) patients were included. Each patient had up to three indications for amputation recorded; for example, a single patient could receive an amputation because of trauma-related infection, which would be charted as 'trauma' and 'infection'. Patients were included if they received a major amputation, defined as above the ankle, above the wrist, or at/above the wrist level. In the case of disarticulations (19 operations), only the first operation was included in the data, and any subsequent formalizations of the amputation were not counted as separate procedures. Furthermore, in a small subset of patients who returned to the operating room on more than one occasion, only the highest level of an amputation was counted, and was included only once. Data was de-identified and files were stored in a secure locked room. Study personnel had access to de-identified data only.

Descriptive statistics are provided, with means (standard deviations; SD) or medians (interquartile ranges; IQR) as appropriate. All analysis was performed using STATA (StataCorp, 14.2, College Station, TX).

\section{Results}

A total of 610 patients underwent 630 major amputations during the study period. Of these, $170(27 \%)$ patients were female, and the median age of the cohort was 39 (IQR 25-55). Of these patients, $345(54.8 \%)$ had infection or gangrene recorded among the indications for amputation, $203(32.2 \%)$ had trauma, $94(14.9 \%)$ had cancer and 67 $(10.6 \%)$ had documented diabetes mellitus (Table 1). There is a male preponderance in all etiologies of amputation except in the diabetic cohort (Table 2): males accounted for 239 of $345(69.3 \%)$ of infectious or gangrenous amputations; 166 $(81.8 \%)$ of the 203 trauma-related amputations; and 51 out of $94(54.3 \%)$ of neoplastic amputations. However, there were more diabetes-related amputations in females than in males, at 37 out of $67(56.1 \%)$. The overall age distribution (Table 3) was similar for males (median: 38, IQR: 26-54) and females (median: 40.5, IQR: 23-56; $\mathrm{P}=0.89$ ). However, women were significantly younger at amputation than men when their amputations were due to diabetes (median age 48 vs 53 years old, $\mathrm{P}=0.004$ ) or trauma (median age 21 vs 30 years old, $\mathrm{P}=0.02$ ).

Below the knee amputations (BKAs) were the most common procedure, accounting for 271 or $43 \%$ of surgeries, followed by above the knee amputations (AKAs) (213, or 33.8\%). Nineteen patients $(3 \%)$ underwent bilateral amputations. Upper extremity amputations were a minority, representing $89(14.1 \%)$ of all procedures, and both above and below elbow amputations were evenly distributed at $51.7 \%$ and $48.3 \%$, respectively.

Table 1. Demographic information of amputees at Kamuzu Central Hospital, Lilongwe, Malawi ${ }^{a}$

\begin{tabular}{|l|l|}
\hline & Amputations, $\mathrm{n}(\%)$ \\
\hline Sex & \\
\hline Male & $444(70.5 \%)$ \\
\hline Female & $170(27.0 \%)$ \\
\hline & \\
\hline Age & \\
\hline Median (IQR) & $39(25,55)$ \\
\hline Indication & \\
\hline Infection & $345(54.8 \%)$ \\
\hline Trauma & $203(32.2 \%)$ \\
\hline Cancer & $94(14.9 \%)$ \\
\hline Diabetes & $67(10.6 \%)$ \\
\hline Burns & $23(3.7 \%)$ \\
\hline Procedure & \\
\hline BKA & $271(43.0 \%)$ \\
\hline AKA & $213(33.8 \%)$ \\
\hline BEA & $43(6.8 \%)$ \\
\hline AEA & $46(7.3 \%)$ \\
\hline $\begin{array}{l}\text { Emergent } \\
\text { provisional } \\
\text { amputation }\end{array}$ & $19(3.0 \%)$ \\
\hline Unknown & $18(2.9 \%)$ \\
\hline Laterality & \\
\hline Unilateral & $592(94 \%)$ \\
\hline Bilateral & $18(2.9 \%)$ \\
\hline & \\
\hline & \\
\hline
\end{tabular}

aNote: because each patient could have more than one indication for procedure, the total number of indications included here exceeds the total number of patients. Furthermore, because a patient could have a bilateral amputation, the total numbers reported below for amputations may exceed the total number of patients. AKA, above the knee amputation; AEA, above the elbow amputation; BEA, below the elbow amputation; IQR, interquartile range.

Table 2. Indications for amputation among males and females ${ }^{a}$

\begin{tabular}{lll}
\hline \multicolumn{1}{c}{ Indication } & Male & Female \\
\hline Infection/gangrene & $239(71.6 \%)$ & $95(28.4 \%)$ \\
Trauma & $166(82.6 \%)$ & $35(17.4 \%)$ \\
Cancer & $51(54.3 \%)$ & $41(45.7 \%)$ \\
Diabetes & $29(43.9 \%)$ & $37(56.1 \%)$ \\
Burns & $15(65.2 \%)$ & $8(34.8 \%)$ \\
\hline
\end{tabular}

In cancer-related amputations, sarcoma was present in 32 (34\%), followed by malignant melanoma in $9(9.6 \%)$ patients, and squamous cell carcinoma in $6(6.4 \%)$. Bone tumours of unspecified type were present in $12(12.8 \%)$ of additional patients, and unspecified malignancies accounted 37.2\% of the remaining neoplastic amputations. Median age at neoplasia-related amputation was 38 (IQR 21-56). 
Table 3. Median age at operation for males and females, overall and by indication for amputation ${ }^{a}$

\begin{tabular}{|l|c|c|c|}
\hline $\begin{array}{c}\text { Primary/ } \\
\text { secondary } \\
\text { indication }\end{array}$ & $\begin{array}{c}\text { Median age, } \\
\text { male }\end{array}$ & $\begin{array}{c}\text { Median age, } \\
\text { female }\end{array}$ & P-value \\
\hline Overall & $38(26,54)$ & $40.5(23,56)$ & 0.90 \\
\hline $\begin{array}{l}\text { Infection/ } \\
\text { gangrene }\end{array}$ & $49(33,60)$ & $48(33,60)$ & 0.75 \\
\hline Trauma & $30(23,39)$ & $21(6,34)$ & 0.02 \\
\hline Cancer & $36.5(18,61)$ & $40(31,56)$ & 0.48 \\
\hline Diabetes & $53(50,62)$ & $48(44,57)$ & 0.004 \\
\hline Burns & $35(20,42)$ & $30(25,50)$ & 0.85 \\
\hline
\end{tabular}

a25\% and $75 \%$ interquartile ranges are in parentheses

\section{Discussion}

This is the first report of the epidemiology of major amputations in Malawian adults, and one of the largest series of major amputations from SSA in the literature. An earlier study of amputations from Malawi, by Banza et al., from Blantyre, studied children aged 0-18 years and found the most common indication for amputation in this study population was congenital limb malformation ${ }^{16}$. We found a predominance of young males with lower extremity amputations in our patient population, in keeping with the findings of other studies in the region. The lower extremity predominates, although the exact distribution of BKAs to AKAs differs slightly. Most studies found BKAs to be most common; however, in Jos, Nigeria, and Nairobi, Kenya, AKA was the most common procedure, at $48.9 \%$ and $55 \%$, respectively ${ }^{17,18}$. The median age in our study, at 39 , is also similar to other reports from central and west Africa ${ }^{17-20}$. Of amputees in Kenya, 59.3\% were younger than 29 years, and in Nigerian studies the average age at amputation ranged from 20 to 44 years ${ }^{13,17,21}$, depending on the study. The relative youth of SSA amputees reflects the disparity in amputation etiologies between LMICs and HICs.

Similar to other studies from the region, we report predominantly traumatic, infectious and neoplastic etiologies in our amputee population. Trauma affected $32 \%$ of our patients, a figure which falls in the middle of those reported elsewhere in the region: $13.1 \%$ in Rwanda ${ }^{19}, 13.5-35.7 \%$ in Kenya $^{10,18}, 10.9-69 \%$ in Nigeria ${ }^{13,17,21-24}, 38.4 \%$ in Tanzania ${ }^{20}$ and $49.9 \%$ in Cote d'Ivoire ${ }^{25}$. The efforts to strengthen orthopaedic trauma care at $\mathrm{KCH}$ through international partnerships have resulted in an increased capacity to perform limb-saving procedures (external fixation, soft tissue flaps, etc.) for open fractures. This has reduced the number of amputations as the fraction of orthopaedic procedures at $\mathrm{KCH}$, despite a rapidly rising burden of road traffic injuries $^{26}$. The variation in the incidence of trauma-related amputations in the region may be attributable to differing regional trauma profiles, health care system capacity and the availability of trained surgical workforce. In our study, infection- or gangrene-related amputations represented $45.6 \%$ of indications, a percentage higher than those reported elsewhere. Most of the studies reviewed above report $5.1-43.9 \%$ of amputations due to infection ${ }^{17-25}$. It is unclear whether this stems from an underlying difference in patient populations or from discrepant etiologic definitions. In our study, the higher than expected number of infection- related amputations is likely due to the conflation of trauma and infection. Without improved diagnostic tools and better clinical correlation, this is impossible to determine precisely. However, as most of the infection-related amputations in our setting likely stem from a traumatic event, such as soft tissue injury, chronic osteomyelitis following a fracture, burn sepsis or animal bites, it is likely that the true proportion of infection-related amputations is lower than that reported.

Diabetes was documented in a minority of our patients $(10.8 \%)$, but the true prevalence of diabetes in our population, and in those from other studies from the region, is likely underestimated ${ }^{27}$, due to the lack of diagnostic adjuncts. The reported prevalence of diabetes in SSA was recently postulated at between $2 \%$ and $14 \%{ }^{28}$, and in a recent study of 1135 patients at a primary care clinic in Lilongwe, $18 \%$ of new patients were diagnosed with diabetes over a 1 -year period ${ }^{29}$. In contrast to diabetic amputees in HICs, our diabetic patients underwent amputations at the median age of 52, with women being significantly younger than men. A study of diabetic patients from Tanzania reported a mean age at the time of amputation to be 55.6 years old 30 . In a 7 -year review of 1841 diabetic patients from Cameroon, the diabetic foot ulcer prevalence was 13\%, mean age of diabetics was 57.3 years, and the incidence of amputation was $16 \%{ }^{31}$. A large study of 1280 nontraumatic major and minor amputations in Cape Town, South Africa, found that $925(72.3 \%)$ of all amputations were in diabetics ${ }^{32}$.

We had limited information on the histopathological characterization of neoplasia-related amputations in ourstudy, and due to the nature of our data collection, confirmation with a pathology review was impossible. The true incidence of bone tumours in Malawi is unknown, but a study from a palliative care centre reported that bone cancers were found in $1.1 \%$ of the 842 patients referred to the institution over a 7-year period, and had a median survival time of 3.7 months from presentation ${ }^{33}$. The aim of neoplasia-related amputations in our study was also impossible to determine, although anecdotal evidence indicates a palliative rather than curative intent. At $15.4 \%$, the proportion of our neoplastic amputations is similar to those reported elsewhere $18,20,22,23,34$; also similarly, the majority of cancers in our study were sarcomas $(34 \%)$. In one study from Kenya, $24 \%$ of patients had tumours at amputation, with $66.6 \%$ of those diagnosed as osteogenic sarcoma ${ }^{18}$. Another study of specifically bone tumours seen in an orthopaedic hospital in Lagos, Nigeria, found that $57.1 \%$ of them were osteosarcomas, followed by malignant fibrous histiosarcoma and chondrosarcoma ${ }^{35}$. In a series of 216 bone tumour patients from Addis Ababa, 51 patients had osteosarcoma $(23.6 \%)^{36}$. A 10-year review of Cameroonian patients found 122 malignant tumours of the extremities, and found that 39\% were osteosarcomas, $27 \%$ malignant non-Hodgkin bone lymphomas and $14.8 \%$ fibrosarcomas ${ }^{37}$.

This study is limited by its retrospective methodology and the absence of outcomes data. Furthermore, operative and anaesthesia logs for 2012, 2013 and 2014 were incomplete, making it impossible to generalize trends in amputations or their etiologies at our institution. Another major limitation inherent in this low resource setting is the lack of availability of clinical charts for these operative patients. Because paper charts were not stored with operative logs, and because of restructuring of the hospital's data storage system, we could https://dx.doi.org/10.4314/mmj.v31i4.5 
not locate hospital charts to cross-reference with operative logs. We therefore do not know how complete our etiologic data were, or what were the patient outcomes. The limited granularity of indications data makes it possible that diabetes and trauma were present in a larger proportion of our patients than is reported. The strengths of this study include its duration, number of cases reported, and the ability to access all of the available operative documentation for the services performing amputations at our institution.

\section{Conclusion}

Amputations in Malawi stem from largely preventable causes, and affect primarily young males in the prime of their lives. Further studies are needed to determine the outcomes and long-term functionality of amputees in the region. The most common etiologies of amputations in this study - trauma and infection-represent important primary prevention targets in this economically vital population.

\section{Authors' contributions}

JG: data acquisition and writing of the manuscript. CM: data acquisition. CM: data acquisition and literature review. SY and LB: writing of the manuscript. BC: critical revision of manuscript. AC: study concept, design and critical revision of manuscript.

\section{Funding}

Availability of data and materials

\section{Competing interests}

\section{References}

1. Payne CF, Mkandawire J, Kohler H-P. Disability transitions and health expectancies among adults 45 years and older in Malawi: a cohort-based model. PLoS Med. 2013;10(5):e1001435. doi: 10.1371/ journal.pmed.1001435.

2. van der Meij WKN. No leg to stand on. Historical relation between amputation surgery and prostheseology. Turnhout: Druk Proost; 1995. $256 \mathrm{p}$.

3. Magee R. Amputation through the ages: the oldest surgical operation. Aust NZ Surg. 1998;68:675-8.

4. Paudel B, Shrestha BK, Banskota AK. Two faces of major lower limb amputations. Kathmandu Univ Med J (KUMJ). 2005;3(3):212-6.

5. Udosen AM, Ngim N, Etokidem A, Ikpeme A, Urom S, Marwa A. Attitude and perception of patients towards amputation as a form of surgical treatment in the University of Calabar teaching hospital, Nigeria. Afr Health Sci. 2009;9(4):254-7.

6. Vos T, Flaxman AD, Naghavi M, Lozano R, Michaud C, Ezzati M, et al. Years lived with disability (YLDs) for 1160 sequelae of 289 diseases and injuries 1990-2010: a systematic analysis for the Global Burden of Disease Study 2010. Lancet. 2012;380(9859):2163-96. doi: 10.1016/ S0140-6736(12)61729-2.

7. Ephraim PL, Dillingham TR, Sector M, Pezzin LE, Mackenzie EJ. Epidemiology of limb loss and congenital limb deficiency: a review of the literature. Arch Phys Med Rehabil. 2003;84(5):747-61.

8. Varma P, Stineman MG, Dillingham TR. Epidemiology of limb loss. Phys Med Rehabil Clin N Am. 2014;25(1):1-8. doi: 10.1016/j. pmr.2013.09.001.

9. Ma VY, Chan L, Carruthers KJ. Incidence, prevalence, costs, and impact on disability of common conditions requiring rehabilitation in the United States: stroke, spinal cord injury, traumatic brain injury, multiple sclerosis, osteoarthritis, rheumatoid arthritis, limb loss, and back pain. Arch Phys Med Rehabil. 2014;95(5):986-95.e1. doi: 10.1016/j.apmr.2013.10.032.
10. Ogeng'o JA, Obimbo MM, King'ori J. Pattern of limb amputation in a Kenyan rural hospital. Int Orthop. 2009;33(5):1449-53. doi: 10.1007/ s00264-009-0810-5.

11. Loro A, Franceschi F. Prevalence and causal conditions for amputation surgery in the third world: ten years experience at Dodoma Regional Hospital, Tanzania. Prosthet Orthot Int. 1999;23(3):217-24. doi: $10.3109 / 03093649909071637$

12. Adegbehingbe OO, Akinyoola AL, Oginni LM. Predictive factors for primary amputation in trauma patients in a Nigerian university teaching hospital. East Afr Med J. 2006;83(10):539-44.

13. Thanni LOA, Tade AO. Extremity amputation in Nigeria-a review of indications and mortality. Surgeon. 2007;5(4):213-7.

14. Malawi Data [Internet]. [cited 2017 May 22]. Available from: http:// data.worldbank.org/country/Malawi.

15. Food and Agriculture Organization of the United Nations [Internet]. General Introduction FAO [cited 2017 May 26]. Available from: http:// www.fao.org/gender-landrights-database/country-profiles/countrieslist/general-introduction/en/?country_iso3=MWI.

16. Banza LN, Mkandawire NC, Harrison WJ. Amputation surgery in children: an analysis of frequency and cause of early wound problems. Trop Doct. 2009;39(3):129-32. doi: 10.1258/td.2009.080192.

17. Kidmas AT, Nwadiaro CH, Igun GO. Lower limb amputation in Jos, Nigeria. East Afr Med J. 2004;81(8):427-9.

18. Awori K, Ating'a J. Lower limb amputations at the Kenyatta National Hospital, Nairobi. East Afr Med J. 84(3):121-6.

19. Murwanashyaka E, Ssebuufu R, Kyamanywa P. Prevalence, indications, levels and outcome limb amputations at University Teaching Hospital-Butare in Rwanda. East Cent Afr J Surg. 18(2):103-7.

20. Chalya P, Mabula J, Dass R, Ngayomela IH, Chandika AB, Mbelenge $\mathrm{N}$, et al. Major limb amputations: a tertiary hospital experience in northwestern Tanzania. J Ortho Surg Res. 2012;7:18.

21. Omoke NI, Chukwu COO, Madubueze CC, Egwu AN. Traumatic extremity amputation in a Nigerian setting: patterns and challenges of care. Int Orthop. 2012;36(3):613-8. doi: 10.1007/s00264-011-1322-7.

22. Umaru H, Madubueze C, Alada A, Onu C. Limb amputations in Nigeria: The national hospital Abuja experience. Niger J Surg Res. 2015;16(1):11-4.

23. Ndukwu C, Muoneme C. Prevalence and pattern of major extremity amputation in a tertiary Hospital in Nnewi, South East Nigeria. Trop J Med Res. 2015;18(2):104-8.

24. Omoke N, Nwigwe C. Limb amputations in Abakaliki, South East Nigeria. Afr J Med Health Sci. 2016;15(1):30-5.

25. Sié Essoh JB, Kodo M, Djè Bi Djè V, Lambin Y. Limb amputations in adults in an Ivorian teaching hospital. Niger $\mathrm{J}$ Clin Pract. 2009;12(3):245-7.

26. Young S, Banza L, Mkandawire N. The impact of long term institutional collaboration in surgical training on trauma care in Malawi. SpringerPlus. 2016;5:407. doi: 10.1186/s40064-016-2050-7.

27. Boulton AJM, Vileikyte L, Ragnarson-Tennvall G, Apelqvist J. The global burden of diabetic foot disease. Lancet. 2005;366(9498):171924. doi: 10.1016/S0140-6736(05)67698-2.

28. Manne-Goehler J, Atun R, Stokes A, Goehler A, Houinato D, Houehanou C, et al. Diabetes diagnosis and care in sub-Saharan Africa: pooled analysis of individual data from 12 countries. Lancet Diabetes Endocrinol. 2016;4(11):903-12. doi: 10.1016/S2213-8587(16)301814.

29. Manjomo RC, Mwagomba B, Ade S, Ali E, Ben-Smith A, Khomani $\mathrm{P}$, et al. Managing and monitoring chronic non-communicable diseases in a primary health care clinic, Lilongwe, Malawi. Public Health Action. 2016;6(2):60-5. doi: 10.5588/pha.16.0003.

30. Viswanathan V, Wadud JR, Madhavan S, Rajasekar S, Kumpatla S, https://dx.doi.org/10.4314/mmj.v31i4.5 
Lutale JK, et al. Comparison of post amputation outcome in patients with type 2 diabetes from specialized foot care centres in three developing countries. Diabetes Res Clin Pract. 2010;88(2):146-50. doi: 10.1016/j.diabres.2010.02.015.

31. Kengne AP, Djouogo CFT, Dehayem MY, Fezeu L, Sobngwi E, Lekoubou A, et al. Admission trends over 8 years for diabetic foot ulceration in a specialized diabetes unit in Cameroon. Int J Low Extrem Wounds. 2009;8(4):180-6. doi: 10.1177/1534734609349704.

32. Dunbar GL, Hellenberg DA, Levitt NS. Diabetes mellitus and nontraumatic lower extremity amputations in four public sector hospitals in Cape Town, South Africa, during 2009 and 2010. South Afr Med J. 2015;105(12):1053-6.

33. Msyamboza KP, Manda G, Tembo B, Thambo C, Chitete L, Mindiera C, et al. Cancer survival in Malawi: a retrospective cohort study. Pan Afr Med J. 2014;19. doi: 10.11604/pamj.2014.19.234.4675.
34. Agu T, Ikwu A. Any pattern changes in major lower limb amputations? A 10-year comparative retrospective study in a private orthopedic and trauma center in the south-east region of Nigeria. Niger J Gen Pract. 2017;15(1):1-6.

35. Adeniran J, Samuel E, Dike O, Olayinka SO, Ayokunle O, Nnodu $\mathrm{OE}$, et al. Bone malignancies in orthopaedic hospital Igbobi Lagos, Nigeria. Niger Postgrad Med J. 2014;21(1):66-7.

36. Wamisho B, Admasie D, Negash B, Tinsay M. Osteosarcoma of limb bones: a clinical radiological and histopathological diagnostic agreement at Black Lion Teaching Hospital, Ethiopia. Malawi Med J. 2009;21(2):62-5.

37. Bahebeck J, Atangana R, Eyenga V, Pisoh A, Sando Z, Hoffmeyer P. Bone tumours in Cameroon: incidence, demography and histopathology. Int Orthop. 2003;27(5):315-7. doi: 10.1007/s00264-003-0480-7. 